\title{
Work characteristics and lifestyle as predictors in the development of chronic non-specific lung disease among elderly municipal employees
}

\author{
L Tammilehto, K Tuomi
}

\begin{abstract}
Objectives-This study prospectively evaluated factors of working conditions and lifestyle in the development of chronic non-specific lung disease (CNSLD).
\end{abstract}

Methods-Baseline data were collected in 1981 from 5386 municipal employees born in 1923-35 who had no diagnosed CNSLD. The subjects were studied again in 1985 with a postal questionnaire. The predictors of CNSLD were selected by multivariate logistic regression analysis. Results-159 (3\%) reported the development of CNSLD confirmed by a physician. During the 4.6 year follow up period the average annual incidence was $6 \cdot 5 / 1000$ subjects. In men the logit model followed was: smoking (odds ratio (OR) $1 \cdot 17,95 \%$ confidence interval (95\% CI) 1.06-1.29), tight work schedule (OR 1.31, 95\% CI 1.03-1.65), loss of a close friend (OR 2.21, 95\% CI 1.13-4.31), and retirement of a spouse (OR 3.31, 95\% CI 1·35-8.11). In women the selected risk factors were: smoking (OR 1.22, 95\% CI 1.01-1.38), atopy (OR 1.99, 95\% CI 1.12-3.53), physically heavy work (OR 1.65, 95\% CI 1.09-2.29), poor physical working conditions such as heat, cold, changing temperature (OR 1.41, 95\% CI 1·13-1·75), and infrequent communication with other people at work (OR 1.25, $95 \% \mathrm{CI}$ 1.05-1.49).

Conclusion-The differences in the predictors of the incidence of CNSLD between men and women were partly explained by different smoking habits, frequency of atopy, and working conditions. In men the significance of life events (loss of close friend and retirement of wife) need further investigation.

(Occup Environ Med 1995;52:134-137)

Finnish Institute of Occupational Health, Department of Epidemiology and Biostatistics, Helsinki, Finland

L Tammilehto

K Tuomi

Correspondence to: Dr Lauri Tammilehto, Department of

Epidemiology and

Biostatistics, Finnish

Institute of Occupational Health, Topeliukstonal aA, FIN-00250 Helsinki, Finland.

Accepted 13 October 1994

Keywords: chronic non-specific lung disease; lifestyle; work conditions

The increased mortality and cost of chronic non-specific lung disease (CNSLD) have accentuated the need for knowledge on the distribution of the disease in the community and its relation to possible risk factors.

Questionnaire diagnoses of bronchial asthma and chronic obstructive disease are based on symptoms typical of bronchial asthma and chronic obstructive lung disease, ${ }^{1}$ self reported diagnoses of disease,,$^{23}$ or self reported physician's diagnoses of disease. ${ }^{4}$

Chronic non-specific respiratory diseases are usually of multiple aetiology, and they are mainly or partly occupational in origin. Those with an occupational exposure to dust, gases, and fumes had an increased incidence of CNSLD. ${ }^{5}$

Tobacco smoking is the most important cause of obstructive lung disease, but variation between people in response to this exposure and the development of disease in non-smokers have indicated that other factors are also involved. ${ }^{6}$ Atopy, even defined as atopic manifestations, is associated with asthma and chronic bronchitis. ${ }^{7}$ The recognition of personal and environmental factors that characterise high risk subjects, and the identification of other predictors, would improve the potential to prevent and control the disease.

Already in 1956, Rees identified the importance of psychological factors in the development of asthma. ${ }^{8} \mathrm{He}$ found that asthmatic people were more often sensitive, timid, and anxious than their non-asthmatic controls. Psychosocial factors are generally thought to cause CNSLDs. ${ }^{9}$ Stress and emotion have been mentioned as triggering factors in asthma. ${ }^{10}$ The role of life events in the development of CNSLD is less clear. The onset of asthma has been reported to follow life events such as bereavement. ${ }^{11}$ Well designed prospective research studies that would decisively prove that psychosocial factors or life events do play a part in the development of CNSLD, have not been done.

The main objective of our study was to examine the connection between the development of CNSLD during the study period and the rate of work and lifestyle factors. The data on the Finnish research project on aging workers in municipal occupations suited this purpose well, because of the numerous variables that described work, lifestyle, and health. ${ }^{12}$
Subjects and methods

SUBJECT SELECTION

The subjects of the research project $(n=6257)$ were born in 1923-35, lived in different parts of Finland, and were active municipal workers with at least five years of experience in their current occupations at the beginning of the study. ${ }^{13}$ They answered a postal questionnaire in 1981 and in 1985 . The response rate was $85 \%$ and $89 \%$ 
respectively. Those subjects who in 1981 did not report bronchitis or asthma diagnosed by a physician $(n=5386)$ were chosen for this study. Questions that were asked on other respiratory diseases in 1981 included "Do you have emphysema?" and "Do you have tuberculosis?" Patients who had these diseases were excluded from the study.

\section{DIAGNOSIS OF DISEASE}

During the follow up 1981-5, the percentage of those diagnosed by a physician with chronic bronchitis or asthma (CNSLD) was $3.0 \%(159 / 5386)$. The dichotomous health outcome variable was: 159 had developed chronic bronchitis or asthma, and 5227 had not. The occurrence of disease was ascertained by the questions: "Do you now have any disease, defect, or injury of long duration?" and "Indicate on the following list what kind of diseases or injuries you have at present. Also indicate whether a physician has diagnosed or treated the above disease." One of the response alternatives was both chronic bronchitis and asthma. The MRC (Medical Research Council) ${ }^{14}$ definition of chronic bronchitis could not be used because the MRC questions were not included in this survey.

\section{RISK FACTORS}

The potential explanatory variables found from the questionnaire at baseline in 1981 have been presented earlier. ${ }^{15}$ They included 72 questions on features of work (physical and psychological demands, possibilities for development, the physical and chemical environment, the organisation and the social environment, changes in work stress during the last two years), 34 questions concerning lifestyle (habits and hobbies, life events during the past half year, living conditions), and questions on life history (smoking, vocational education, change of occupation). The variables of work described either its prevalence or harmfulness.

Sex, age, smoking, atopy, and work content were treated as confounders (table 1). Subjects were classified in 1981 as nonsmokers if they have never smoked daily for as much as one year. Exsmokers were those who had been smoking for more than one year and had given up before the survey. Current smokers were those who had been smokers for more than one year and were still smokers.
The respondent was classified as atopic if he or she at the time of the questionnaire had chronic rhinitis or allergic eczema confirmed by a physician. Asthma was not included in the definition of atopy because it was the dependent variable. The subjects were selected from three categories of work content: physical (auxiliary, home care, and installation work), mixed (transportation, nursing, kitchen supervision, dentistry, and dump work), and mental (office, administration, teaching, technical supervision, and physician) by the "ergonomic job analysis procedure", Arbeitswissenschaftliche Erhebungsverfahren zur Tätigkeitsanalyse (AET) method. ${ }^{16}$ The AET method incorporates observations of the work and interviews of the workers and foremen. The work content groups were different for men and women. Installation work, transportation, dump work, administrative work, and technical supervision were almost purely men's work categories, whereas home care, nursing, and kitchen supervision were purely women's groups.

At baseline in 1981 more men smoked than women. Of the men, $31 \%$ had never smoked, $44 \%$ were exsmokers and $25 \%$ were current smokers; the corresponding figures for women were $77 \%, 16 \%$, and $7 \%$. Women had more atopic symptoms than men: $9 \%$ (280) of women and $6 \%$ (133) of men were classified as atopic. The work content of $48 \%$ of the men but only of $36 \%$ of the women was physical. The group of mixed mental and physical work contained $25 \%$ of the men and $35 \%$ of the women, whereas $27 \%$ of the men and $29 \%$ of the women were in the group of purely mental work.

\section{STATISTICAL ANALYSIS}

The statistical analyses were as follows: all variables were first included in a fixed discriminate analysis between the incidence and CNSLD, the outcome variable. Next, those variables where the $F$ test probability for predicting CNSLD was $\leqslant 5 \%$, were chosen for backward stepwise discriminate analyses. These analyses excluded variables that had a weak discriminative power within the potential risk factor groups of correlated variables. ${ }^{1718}$ The remaining variables and other confounding factors except sex were included in the stepwise logistic regression analysis. ${ }^{18}$ The multifactorial analysis was performed separately for men and women.

\section{Results}

Of the 5386 subjects at risk, 159 reported in the second questionnaire that they had CNSLD confirmed by a physician. This gave an average annual incidence of $6 \cdot 5 / 1000$ subjects.

Univariate analysis showed that sex and age did not significantly associate with the development of CNSLD (table 1). Smoking and atopy were associated with an increasing incidence of CNSLD, specially among women. Men who were in the mixed work category
Mixed p

All

«No chronic bronchitis or bronchial asthma in 1981. 
$(5 \cdot 2 \%)$ had a higher risk of CNSLD than did men in the mental work category $(1.8 \%)$. Women in the physical work category $(4 \cdot 7 \%)$ had higher risk of CNSLD than women in the mental work category $(1 \cdot 7 \%)$.

The univariate analysis of work factors showed that, above all, physical and psychological work demands and the physical and chemical work environment had an effect on the development of CNSLD (table 2).

Among lifestyle factors during the past half year, own unemployment, loss of a close friend, and retirement of spouse were associated significantly with the development of CNSLD (table 2).

Table 3 shows the best fitting multivariable models calculated by stepwise logistic regression analysis.

In men smoking was confirmed as a risk factor in the model. As well as this, tight work schedules, loss of a close friend, and retirement of wife were associated with a high incidence of CNSLD.

In women, smoking and atopy were confirmed by the model. The risk factors at work that were noted in the work environment (physical and psychological) were physically heavy work, poor communications with other

Table 2 Independent variables in 1981 and their associations with the development of chronic bronchitis or bronchial asthma among all subjects ( $n=5386 ; F$ tests and their significance; $-=$ preventive effect)

\begin{tabular}{|c|c|c|}
\hline & $F$ test & Pvalue \\
\hline \multicolumn{3}{|l|}{ Work: } \\
\hline \multicolumn{3}{|l|}{ Physical: } \\
\hline Sudden exertion $\dagger$ & $23 \cdot 7$ & $\star \star \star$ \\
\hline Physically heavy work & $20 \cdot 5$ & $\star \star \star$ \\
\hline Difficult and uncomfortable posturest & $20 \cdot 4$ & $\star \star \star$ \\
\hline Whole body exertion & $18 \cdot 6$ & $\star \star \star \star$ \\
\hline Bent or twisted postures & $16 \cdot 3$ & $\star \star \star \star$ \\
\hline Carrying objects by hand & $13 \cdot 5$ & $\star \star \star$ \\
\hline Frequent walking or moving & $7 \cdot 5$ & $\star \star$ \\
\hline Repetitive movements & 5.9 & $\star$ \\
\hline \multicolumn{3}{|l|}{ Psychological: } \\
\hline Paced work & $14 \cdot 3$ & $\star \star \star \star$ \\
\hline Tight time schedulet & $11 \cdot 0$ & $\star \star \star \star$ \\
\hline Communication with other people & -9.6 & $\star \star$ \\
\hline Monotonous and uninteresting work $\dagger$ & $6 \cdot 1$ & $\star \star$ \\
\hline Responsibility in work $t$ & $4 \cdot 1$ & $\star$ \\
\hline \multicolumn{3}{|c|}{ Possibilities for development and influence: } \\
\hline Planning own work & $-6 \cdot 2$ & $\star \star$ \\
\hline Applying own abilities & $-4 \cdot 2$ & $\star$ \\
\hline Learning new things and education & -3.9 & * \\
\hline \multicolumn{3}{|l|}{ Physical and chemical environment: } \\
\hline Dust, smoke, steam, etc† & $31 \cdot 5$ & $\star \star \star$ \\
\hline Heat, cold, changing temperature $f$ & $28 \cdot 5$ & $\star \star \star$ \\
\hline Dirtinesst & $22 \cdot 6$ & $\star \star \star \star$ \\
\hline Poor lighting, glare & $20 \cdot 4$ & $\star \star \star \star$ \\
\hline Draught & $19 \cdot 9$ & $\star \star \star \star$ \\
\hline Risk of accident $†$ & $18 \cdot 7$ & $\star \star \star \star$ \\
\hline Dryness, dampness $\dagger$ & $17 \cdot 7$ & $\star \star \star$ \\
\hline Acids, alkalis, solvents, oils, etc & $12 \cdot 2$ & $\star \star \star$ \\
\hline Restless environment, noisy peoplet & $9 \cdot \overline{2}$ & $\star \star$ \\
\hline \multicolumn{3}{|l|}{ Organisation and social environment: } \\
\hline Quality and quantity of tools $\ddagger$ & $11 \cdot 4$ & $\star \star \star \star$ \\
\hline Tasks and responsibility inconsistent $\dagger$ & 8.8 & $\star \star$ \\
\hline Safety equipment $\neq$ & $5 \cdot 6$ & $\star$ \\
\hline Rest breaks $\ddagger$ & $4 \cdot 8$ & $\star$ \\
\hline Possibility for meals at work $\neq$ & $5 \cdot 4$ & * \\
\hline \multicolumn{3}{|l|}{ Lifestyle: } \\
\hline \multicolumn{3}{|l|}{ Life events in the last half year: } \\
\hline Own unemployment & $12 \cdot 0$ & $\star \star \star$ \\
\hline Loss of a close friend & $7 \cdot 1$ & $\star \star$ \\
\hline Retirement of spouse & $8 \cdot 7$ & $\star \star \star$ \\
\hline \multicolumn{3}{|l|}{ Living conditions: } \\
\hline $\begin{array}{l}\text { Number of unemployed household } \\
\text { members over } 15 \text { years of age }\end{array}$ & $-5 \cdot 5$ & $\star$ \\
\hline Poor economy & $4 \cdot 3$ & 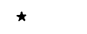 \\
\hline \multicolumn{3}{|l|}{ Education, change of occupation: } \\
\hline Age at first employment & $-11 \cdot 9$ & $\star \star \star$ \\
\hline Vocational education & $-6 \cdot 8$ & $\star \star \star$ \\
\hline Best age for work (measured in 1985) & $-6 \cdot 7$ & $\star \star$ \\
\hline
\end{tabular}

Table 3 Variables related to 4.6 year incidence of CNSLD with a logistic regression model in men $(n=2321)$ and women $(n=3065)$ (Finnish municipal employees born in 1923-35)

\begin{tabular}{|c|c|}
\hline Variables & OR $(95 \% C I)$ \\
\hline \multicolumn{2}{|l|}{ Men: } \\
\hline Smoking & $1.17(1.06-1.29)$ \\
\hline Tight work schedule & $1.31(1.03-1.65)$ \\
\hline Loss of a close friend & $2 \cdot 21(1 \cdot 13-4 \cdot 31)$ \\
\hline Retirement of wife & $3 \cdot 31(1 \cdot 35-8 \cdot 11)$ \\
\hline \multicolumn{2}{|l|}{ Women: } \\
\hline Smoking & $1.22(1.01-1.38)$ \\
\hline Atopy & $1.99(1.12-3.53)$ \\
\hline Physically heavy work & $1.65(1.09-1.49)$ \\
\hline \multicolumn{2}{|l|}{ Infrequent communication with other } \\
\hline $\begin{array}{l}\text { people at work } \\
\text { Heat, cold, changing temperature at }\end{array}$ & $1.25(1.05-$ \\
\hline work & $1.41(1.13-1.75)$ \\
\hline
\end{tabular}

Table 4 Incidence of CNSLD by level of work related factors and life events in univariate analysis, in men and women, adjusted by smoking (Finnish municipal employees born in 1923-35)

\begin{tabular}{|c|c|c|}
\hline & $n$ & Incidence \\
\hline \multicolumn{3}{|l|}{ Men: } \\
\hline \multicolumn{3}{|c|}{ Tight work schedule: } \\
\hline Never & 505 & $2 \cdot 7$ \\
\hline Seldom & 647 & $2 \cdot 2$ \\
\hline Sometimes & 780 & $4 \cdot 3$ \\
\hline Often & 389 & $5 \cdot 1$ \\
\hline \multicolumn{3}{|c|}{ Loss of a close friend: } \\
\hline No & 2156 & $3 \cdot 2$ \\
\hline Yes & 165 & $7 \cdot \overline{3}$ \\
\hline \multicolumn{3}{|c|}{ Retirement of wife: } \\
\hline No & 2263 & $3 \cdot 3$ \\
\hline Yes & 58 & $9 \cdot 0$ \\
\hline \multicolumn{3}{|l|}{ Women: } \\
\hline \multicolumn{3}{|l|}{ Atopy: } \\
\hline No & 2785 & $3 \cdot 1$ \\
\hline Yes & 280 & $8 \cdot 6$ \\
\hline \multicolumn{3}{|c|}{ Physically heavy work: } \\
\hline Light & 1662 & $2 \cdot 1$ \\
\hline Moderate & 1143 & $4 \cdot 0$ \\
\hline Too heavy & 260 & $11 \cdot 0$ \\
\hline \multicolumn{3}{|c|}{ Communication with other people at work: } \\
\hline Never & 85 & $5 \cdot 7$ \\
\hline Seldom & 177 & $9 \cdot 8$ \\
\hline Sometimes & 674 & 5.9 \\
\hline Often & 572 & $3 \cdot 1$ \\
\hline & & $2 \cdot 0$ \\
\hline \multicolumn{3}{|c|}{ Heat, cold, changing temperature at work: } \\
\hline Never & 1201 & $1 \cdot 7$ \\
\hline Seldom & 639 & $4 \cdot 6$ \\
\hline Sometimes & 867 & $3 \cdot 3$ \\
\hline Often & 357 & $9 \cdot 0$ \\
\hline
\end{tabular}

people at work, heat, cold, and changing temperature in the workplace.

Table 4 depicts the cumulative annual incidence of CNSLD, adjusted for smoking, for increasing levels of the univariate predictors identified in the final model that showed a dose-response effect. In male smokers loss of a close friend (OR $3 \cdot 19,95 \%$ CI $1 \cdot 29-7 \cdot 85$ ) and retirement of wife (OR 3.49, 95\% CI $1 \cdot 19-10 \cdot 15)$ were significantly associated with development of CNSLD. In other men the association was not significant (OR 2.62, 95\% CI $0 \cdot 64-10 \cdot 71$, OR $1 \cdot 76,95 \%$ CI 0.69-4.49, respectively) mainly because of small numbers of cases.

\section{Discussion}

In this prospective study we investigated the relation between development of diagnosed CNSLD and working conditions and lifestyle. The study population consisted of 5386 Finnish municipal employees born in 1923-35. The number of non-respondents was low ( $15 \%$ in 1981 and $11 \%$ in 1985). Because the categories of work, smoking 
habits, and prevalence of atopy were quite different in men and women multivariate analyses were done separately for men and women.

The incidence of CNSLD was associated with smoking and atopy, as is well known. In women, along with smoking and atopy, physically heavy work, heat, cold, changing temperature, and infrequent communication with other people at work independently predicted the development of CNSLD. Blue collar workers have had a higher prevalence for several of the respiratory symptoms and even for diagnosed CNSLD, than white collar workers. ${ }^{19}$ Heat, cold, and changing temperature at work reflected poor physical working conditions that are usually associated with outdoor work, dust, etc. Many municipal workers may have a high exposure to organic or inorganic dust - for example, carpenter, dump and park worker, streetsweeper, construction workerand also to indoor respiratory allergens-for example, cleaner, domestic help, housekeeper, hospital aid, painter, mechanic, janitor). Heat and outdoor work have been strongly related to diagnosed CNSLD. ${ }^{19}$ People with occupational exposure to dust or gases have an increased risk of CNSLD. ${ }^{20}$ Also in incidence studies, occupations that involve dusty work have a high risk of CNSLD. ${ }^{5}$

In men, smoking, tight work schedules, loss of a close friend, and retirement of wife were independently associated with the development of CNSLD. Tight time schedules among men, and in women infrequent communication with other people at work represent poor psychological working conditions and mental stress that may exacerbate asthma. ${ }^{10}$ Stressful life events such as the illness, death, or fear of losing a close relative or friend, or the feeling of loneliness have preceded outbreaks of asthma. ${ }^{11}$

This prospective study confirmed earlier results that smoking, atopy, and working conditions influenced the development of CNSLD. Stressful work (physically heavy work, poor physical working conditions, infrequent communication with other people at work, tight work schedule) and social life (loss of a close friend, retirement of spouse) may precede the development of CNSLD. It is difficult to generalise these results in terms of risks attributable to populations related to work characteristics and life events. The num- ber of cases was small for selection by age and employment and the follow up time was short. The significance of psychosocial factors (loss of a close friend and retirement of wife), especially in men, on incidence of CNSLD needs further investigation.

We express our sincere thanks to Erkki Nykyri, MSc, who helped with the logistic regression.

1 Samet JM, Schrag SD, Howard CA, Key CR, Pathak DR. Respiratory disease in a New Mexico sample of Hispanic and non-Hispanic whites. Am Rev Respir Dis 1982;125: and no.

2 Lebowitz MD, Knudson RJ, Burrows B. Tucson epidemiologic study of obstructive lung diseases. I: Methodology and prevalence of disease. Am $\mathcal{f}$ Epidemiol 1975;102: 137-52.

3 Lundbäck B, Nyström L, Rosenhall L, Stjernberg N. Obstructive lung disease in northern Sweden: respiratory symptoms assessed in a postal survey. Eur Respir f 1991; 4:257-66.

4 Gulsvik A. Obstructive lung disease in an urban population. Oslo, Reprografisk Industri A/S. 1979.

5 Heederik D, Kromhout $\mathrm{H}$, Burema J, Biersteker $\mathrm{K}$, Kromhout D. Occupational exposure and 25-year inciKromhout $\mathrm{D}$. Occupational exposure and 25-year inci-
dence rate of non-specific lung disease-the Zutphen dence rate of non-specific lung disease-

6 US Department of Public Health and Human Services. The health consequences of smoking. Cancer and chronic obstructive lung disease in the workplace. Washington: Government Printing Office, 1985.

7 Terho EO, Husman K, Vohlonen K. Prevalence and incidence of chronic bronchitis and farmer's lung with respect to age, sex, atopy and smoking. Eur $\mathcal{F}$ Respir Dis 1987; (suppl):19-28.

8 Rees L. Psychical and emotional factors in bronchial asthma. F Psychosom Res 1956;1:98-114.

9 Thompson WL, Thompson TL. Somatization and pulmonary disease. Psychiatr Med 1992;10:77-91.

10 Bienenstock J. Summing up: present concepts and future ideas on immunoregulation of asthma. Eur Respir $\mathcal{f}$ 1991;4(suppl 13):154-60.

11 Levitan $\mathrm{H}$. Onset of asthma during intense mourning. Psychosomatics 1985;26:939-41.

12 Ilmarinen J, ed. The aging worker. Scand $\mathcal{f}$ Work Environ Health 1991;17(suppl 1):141.

13 Tuomi K, Toikkanen J, Eskelinen L, Backman A-L, Ilmarinen J, Järvinen E, Klockars M. Mortality, disability and changes in occupation among municipal employees. Scand $f$ Work Environ Health 1991;17(suppl 1):58-66.

14 Medical Research Council's committee on the aetiology of chronic bronchitis. Standardized questionnaires on chronic bronchitis. Standardized question

15 Tuomi K. Characteristics of work and life predicting coronary heart disease. Finnish research project on aging workers. Soc Sci Med 1994;38:1509-19.

16 Ilmarinen J, Suurnäkki T, Nygård C-H, Landau K. Classification of municipal occupations. Scand $\mathcal{f}$ Work Environ Health 1991;17(suppl 1):12-29.

17 Anderson S, Auquier A, Hauck WW, Oakes P, Vandaele W, Weisberg HI. Statistical methods for comparative studies. Techniques for bias reduction. New York: John Wiley, 1980.

18 SAS/STAT. Users's guide, version 6, 4th ed. Vol 2. Cary, NC: SAS Institute, 1990

19 Heederik D, Pouwles H, Kromhout H, Kromhout D. Chronic non-specific lung disease and occupational exposures estimated by means of a job exposure matrix: the Zutphen study. Int $\mathcal{F}$ Epidemiol 1989;18:382-9.

20 Bakke P, Eide GE, Hanoa R, Gulsvik A. Occupational dust or gas exposure and prevalences of respiratory symptoms and asthma in a general population. Eur Respir f 1991;4:273-8. 